\title{
CHEMOSPHERE
}

\section{Leaching of 2,4-D from a soil in the presence of $\beta$-cyclodextrin: laboratory columns experiments}

\author{
E. Morillo ${ }^{\mathrm{a}, *}$, J.I. Pérez-Martínez ${ }^{\mathrm{a}, \mathrm{b}}$, J.M. Ginés ${ }^{\mathrm{b}}$ \\ a Instituto de Recursos Naturales y Agrobiología de Sevilla (CSIC), Apdo. 1052, 41080 Sevilla, Spain \\ ${ }^{\mathrm{b}}$ Departamento de Farmacia y Tecnología Farmacéutica, Universidad de Sevilla, 41012 Sevilla, Spain
}

Received 10 May 2000; accepted 26 July 2000

\begin{abstract}
This study reports on the effect of the presence of $\beta$-cyclodextrin ( $\beta-C D)$ on the adsorption and mobility of the pesticide 2,4-dichlorophenoxyacetic acid (2,4-D) through soil columns. The previous application of $\beta$-CD to the soil produced a retarded leaching of 2,4-D through the soil column, due probably to herbicide adsorption on the soil through $\beta$-CD adsorbed. However, the application of $\beta$-CD solution to the soil column where 2,4-D had been previously adsorbed, led to the complete desorption of the herbicide, due to the formation of water-soluble 1:1 inclusion complexes between 2,4-D and $\beta$-CD. $\beta$-CD can be viewed as a microscopic organic-phase extractant. It can be an advantage to remove from soil pesticides which are able to form inclusion complexes with cyclodextrins, making them possible candidates for use in in situ remediation efforts. (c) 2001 Elsevier Science Ltd. All rights reserved.
\end{abstract}

Keywords: Cyclodextrin; 2,4-D; Leaching; Soil columns

\section{Introduction}

Cyclodextrins (CDs) are cyclic oligosaccharides produced by the microbially induced breakdown of starch. CDs have doughnut-shaped cavities, with a hydrophobic interior cylindrical cavity and hydrophilic faces, which allow the selective accommodation of a variety of guest molecules or ions according to their size and polarity (Szejtli, 1982).

Due to the low-cost production of some of these CDs in recent years, they have received considerable attention in various applied fields (biotechnology, organic chemistry, drugs, foods, pesticides, etc.). The complexation of pesticides may result in considerable improvement of

\footnotetext{
${ }^{*}$ Corresponding author. Tel.: +34-954-624711; fax: +34954-624002.

E-mail address: morillo@irnase.csic.es (E. Morillo).
}

their properties, such as enhancement of solubility and bioavailability (Wang and Brusseau, 1995), increase in stability of volatile and/or unstable pesticides (Kamiya and Nakamura, 1995), diminution of unpleasant taste and odour (Szente, 1998), and reduction of contact toxicity to humans (Loukas et al., 1994).

2,4-Dichlorophenoxyacetic acid (2,4-D) is a widely used, non-selective herbicide which is applied mainly against broad-leaved weeds in cereal and other crops, although it is also used as plant growth regulator. It has been previously reported that its interaction with $\beta-C D$ produced the formation of a new inclusion compound in solution and in solid state that improved the solubility and dissolution rate of this pesticide (Ginés et al., 1996). The effect of $\beta$-CD on 2,4-D soil adsorption-desorption has been also studied by batch equilibration experiments (Pérez-Martínez et al., 1999). In the present research, 2,4-D mobility through soil columns was investigated as affected by the presence of $\beta-C D$ in solution and adsorbed on the soil. 


\section{Experimental}

2,4-D was supplied by Sigma (St. Louis, Missouri, USA), and $\beta$-CD by Roquette (Lestrem, France). $\beta-C D$ solubility is $18.5 \mathrm{~g} \mathrm{l}^{-1}$ and its molecular weight 1135 . The soil used was classified as an Alfic Dystric Eutrocrept, from Huelva (Spain), being principally constituted by iron oxides (Pérez-Rodríguez et al., 1996). Soil sample was crushed to pass a $2 \mathrm{~mm}$ sieve. The properties of the soil used in the investigation are given in Table 1. All other materials used were analytical reagent grade.

Experiments in handpacked soil columns were carried out under saturated flow conditions. Columns were constructed from PVC pipe and were $15 \mathrm{~cm}$ long $\times$ $5 \mathrm{~cm}$ inner diameter. They were packed uniformly with $150 \mathrm{~g}$ of air-dried soil, which occupied about $10 \mathrm{~cm}$ of the column. The pore volume was calculated to be $80 \mathrm{ml}$. Columns were conditioned by passing through them about 5 pore volumes of $0.01 \mathrm{M} \mathrm{KNO}_{3}$ solution, using a flow rate of $1 \mathrm{ml} \mathrm{min} \mathrm{m}^{-1}$ controlled by a peristaltic pump. This was followed by four different experiments (in duplicate) as described below.

\subsection{Experiment I}

In order to determine the leaching of 2,4-D through the soil column, 1 pore volume $(80 \mathrm{ml})$ of $2,4,-\mathrm{D}$ aqueous solution $\left(500 \mathrm{mg} \mathrm{l}^{-1}\right)$ was applied to the top of the column. The solution remained in contact with the soil during $24 \mathrm{~h}$. After that, $750 \mathrm{ml}$ of $\mathrm{KNO}_{3}$ solution $(0.01$ $\mathrm{M})$ was used as eluent until no more 2,4-D was detected in the leachate. Finally, the column was eluted with $250 \mathrm{ml}$ of $0.01 \mathrm{M} \beta-\mathrm{CD}$ solution.

\subsection{Experiment $I I$}

In order to study the influence of $\beta-C D$ on the pesticide 2,4-D previously adsorbed, the column was treated with $80 \mathrm{ml}$ of 2,4-D aqueous solution $\left(500 \mathrm{mg} \mathrm{l}^{-1}\right)$ remaining in contact with the soil during $24 \mathrm{~h}$. After that the pesticide was eluted, but in this case the eluent used was 11 of $0.01 \mathrm{M} \beta-\mathrm{CD}$ solution.

Table 1

Some properties of the soil studied

\begin{tabular}{lc}
$\mathrm{pH}$ & 6.0 \\
Humidity $(\%)$ & 2.95 \\
OM $(\%)$ & 1.41 \\
$\mathrm{CEC}(\mathrm{cmol} / \mathrm{kg})$ & 12.36 \\
Sand $(\%)$ & 17.0 \\
Silt $(\%)$ & 58.0 \\
Clay $(\%)$ & 25.0 \\
Total Fe $(\%)$ & 35.68 \\
Total $\mathrm{Al}(\%)$ & 14.82 \\
\hline
\end{tabular}

\subsection{Experiment III}

In order to determine if the presence of $\beta-C D$ in soil influences the leaching of 2,4-D, 1 pore volume $(80 \mathrm{ml})$ of $0.01 \mathrm{M} \beta-\mathrm{CD}$ solution was applied to the top of the column, remaining in contact with the soil during $24 \mathrm{~h}$, separating then the $\beta-C D$ solution from the soil. The column was then treated with 1 pore volume of 2,4-D aqueous solution $\left(500 \mathrm{mg}^{-1}\right)$, remaining in contact with the soil during $24 \mathrm{~h}$. After that, 11 of $0.01 \mathrm{M} \mathrm{KNO}_{3}$ solution was used as eluent.

\subsection{Experiment IV}

In order to observe the leaching of 2,4-D when it is put in contact with $\beta-C D$ in aqueous solution before being applied to the soil column, an aqueous solution containing $\beta$-CD $11.35 \mathrm{~g} \mathrm{l}^{-1}(0.01 \mathrm{M})$ and 2,4-D (500 mg $1^{-1}$ ) was prepared. It leads to the formation of the complex $2,4-\mathrm{D}-\beta-\mathrm{CD}$ in solution. Then, 1 pore volume of this solution was applied to the top of the column, remaining in contact with the soil during $24 \mathrm{~h}$. After that, 11 of $0.01 \mathrm{M} \mathrm{KNO}_{3}$ solution was used as eluent.

Column leachate in each experiment was collected using a fraction collector in $8 \mathrm{ml}$ fractions, and 2,4-D was analysed spectrophotometrically at $284 \mathrm{~nm}$.

\section{Results and discussion}

The results obtained from soil columns experiments have been represented in the form of breakthrough curves (BTC), in which the amount of 2,4-D released $(\mathrm{mg})$ in each collected fraction is presented as ordinate in relation to the cumulative volume of eluent applied, presented as abscissa. The results obtained from Experiment I are shown in BT curve of Fig. 1. The total amount of 2,4-D eluted using $0.01 \mathrm{M} \mathrm{KNO}_{3}$ solution as

2,4-D released $(\mathrm{mg})$

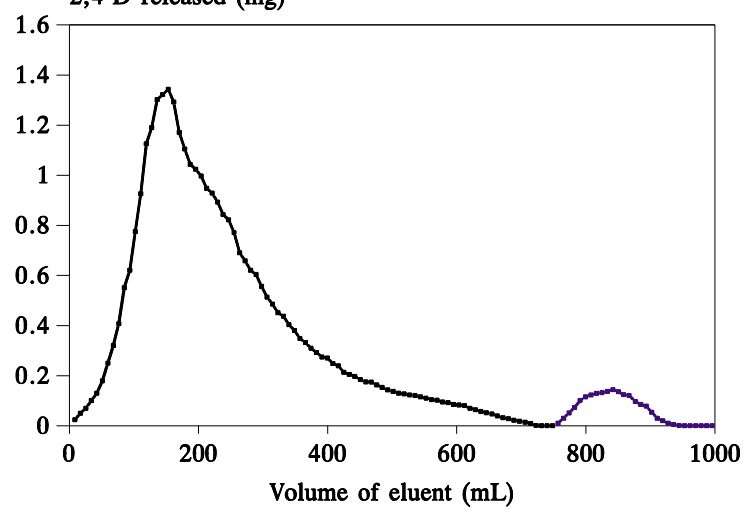

Fig. 1. Breakthrough curve of 2,4-D eluted in Experiment I. 
eluent was $83 \%$ of that previously applied to the column. After that, $250 \mathrm{ml}$ of $0.01 \mathrm{M} \beta$-CD solution was applied to the column as eluent, removing the rest of 2,4-D that could not be removed with $\mathrm{KNO}_{3}$ solution. This behaviour can be due to the tendency that presents 2,4-D to form inclusion complexes with $\beta-\mathrm{CD}$, such as it has been previously reported (Ginés et al., 1996). The formation of this complex of stoichiometry 1:1 soluble in water gives as result a facilitated 2,4-D desorption from the soil. So, $\beta-C D$ can be considered as an organic phase acting as an extractant, as it was demonstrated previously, using batch equilibration experiments (PérezMartínez et al., 1999).

Fig. 2 shows the 2,4-D elution curve obtained during the Experiment II, in which a $\beta$-CD solution has been used as eluent. The most notorious feature observed was that the percentage of 2,4-D eluted reached $100 \%$. Besides, Fig. 2 shows that a large proportion of the 2,4-D added is released as in the Experiment $\mathrm{I}$, but a part of the herbicide seems to be more strongly retained in the column and is eluted later. The maximum observed at about $750 \mathrm{ml}$ of elution volume (Fig. 2) seems to indicate that another species (besides free 2,4-D) is being eluted from the column, probably the $2,4-\mathrm{D}-\beta-\mathrm{CD}$ complex.

A factor that is usually used to compare the transport of a solute through soil columns under different conditions is the retardation factor, $R_{\mathrm{F}}$, expressed here as the number of pore volumes required to leach $50 \%$ of the pesticide added to the column (Johnson and Farmer, 1993). $R_{\mathrm{F}}$ was found to be higher when elution was carried out using $\beta$-CD solution (2.9, Experiment II) than using $\mathrm{KNO}_{3}$ solution (2.0, Experiment I).

To test the influence of $\beta$-CD present in soil in 2,4-D release through the column, Experiment III was carried out. The BTC obtained (Fig. 3) shows a significant tailing, more extensive than that of Experiments I and II, and the maximum value of 2,4-D released is below $0.7 \mathrm{mg}$, very low in comparison with the maximum ob-

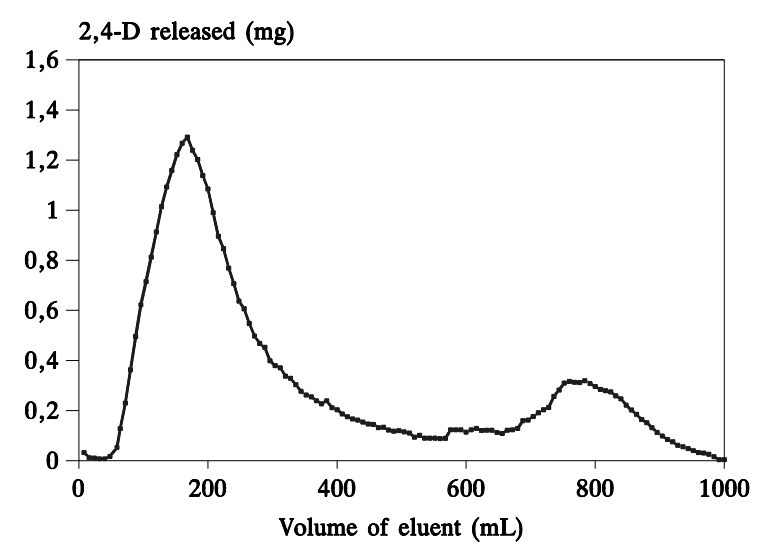

Fig. 2. Breakthrough curve of 2,4-D eluted in Experiment II.

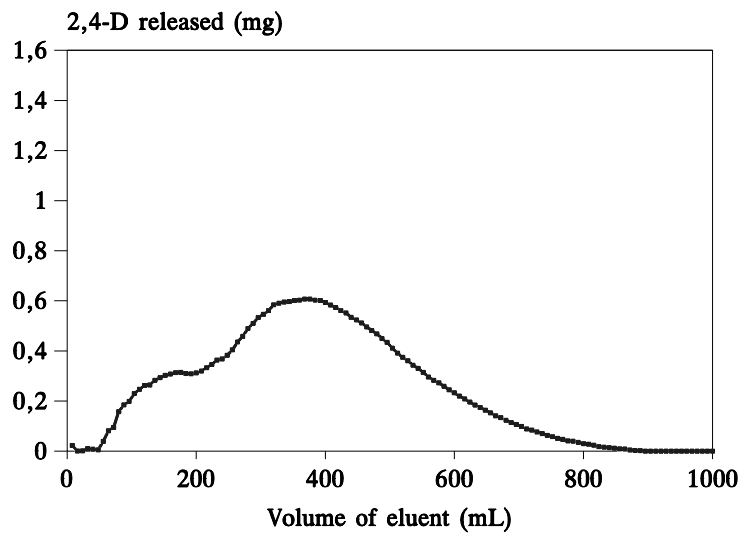

Fig. 3. Breakthrough curve of 2,4-D eluted in Experiment III.

tained in Experiments I and II (close to $1.4 \mathrm{mg}$ ). The percentage of 2,4-D eluted was less than $70 \%$. The retardation factor in this case was much higher, 4.7, indicating that 2,4-D transport through the soil column was more impeded.

This increased value of $R_{\mathrm{F}}$ when $\beta-\mathrm{CD}$ solution is applied before the pesticide can be due in part to an adsorption of $\beta-\mathrm{CD}$ molecules to the soil. In fact, in a previous paper (Pérez-Martínez et al., 1999) the adsorption of $\beta-C D$ on the soil under study in this paper had been demonstrated by batch experiments, indicating also that this adsorption gave as result an increased adsorption of 2,4-D. This is contrary to the results obtained by Brusseau et al. (1994) who did not observe retardation during the release of HP- $\beta-C D$ through soil columns, concluding that the adsorption of this $\mathrm{CD}$ to the soil was not taking place.

This behaviour is similar to that observed for some organic compounds, such as surfactants (Abdul and Gibson, 1991) and dissolved organic matter (Abdul et al., 1990; Magee et al., 1991; Dunnivant et al., 1992), used to promote the desorption and transport of organic contaminants through the soils. Frequently, they also present adsorption on the soil, leading to a retardation in the contaminant release and diminishing their efficiency as extracting agents. Besides, the adsorption of the decontaminant agent can also lead to an increased adsorption of the contaminant, and, consequently, to its retardation in transport through the soil. It can also be what is happening with 2,4-D adsorption on this soil treated previously with $\beta$-CD.

The reason of this behaviour is again the complex formation between 2,4-D and $\beta-C D$, regardless of whether the latter is adsorbed in the soil (as found in Experiment III) or in solution (as found in Experiment II). 2,4-D can form complex with $\beta$-CD molecules adsorbed on the soil, taking place an indirect adsorption of the pesticide to the soil. On the other hand, $\beta$-CD molecules 
that release into solution present a high tendency to form inclusion complexes with 2,4-D. The transport of $\beta-\mathrm{CD}-2,4-\mathrm{D}$ complexes through soil columns by $\mathrm{KNO}_{3}$ solution is more impeded, in relation to free $2,4-\mathrm{D}$, due to its larger size, lower negative charge, etc.

In Experiment IV the pesticide 2,4-D is put into contact with $\beta-C D$ in aqueous solution. It produces the formation of a new inclusion compound, 2,4-D- $\beta-C D$, in solution (Ginés et al., 1996). The behaviour of 2,4-D- $\beta$ CD complex previously formed in solution has been studied in relation to its mobility through soil columns using $0.01 \mathrm{M} \mathrm{KNO}_{3}$ solution as eluent. The BTC is shown in Fig. 4, and the retardation factor obtained was 2.3. It indicates that when 2,4-D is forming complex with $\beta-\mathrm{CD}$ in solution (Experiment IV), its adsorption on the soil is lower than in the case of complex formation with $\beta-C D$ previously adsorbed on the soil (Experiment III). The results obtained in this latter experiment are similar to the Experiment II, in which 2,4-D applied to the soil column was eluted with $\beta$-CD solution. In that case, $\beta$-CD formed a complex with 2,4-D, which was in the soil column, and it was eluted as such a complex, the same as in this case (Experiment IV). When the complex is formed, in both cases is eluted the totality of the pesticide applied to the column, indicating again that the presence of $\beta-C D$ in solution leads to the complete desorption of the pesticide present in the soil.

There seems to exist a controversy between the great effect of $\beta-\mathrm{CD}$ to enhance 2,4-D desorption from this soil, and the fact that $\beta-C D$ adsorbed on the soil acts as a sequestrating agent towards 2,4-D when the former is applied previously, giving a slow transport through the soil. However, this behaviour has been previously observed in several cases. In atrazine application in the presence of dissolved organic matter in the soil (Businelli, 1997), the treatment with such organic matter immediately after atrazine application enhanced the herbicide desorption, but soil treatment with the organic

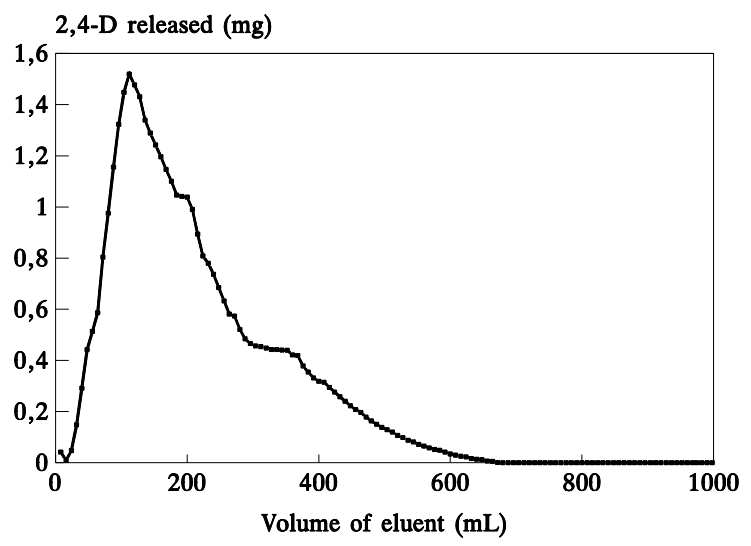

Fig. 4. Breakthrough curve of 2,4-D eluted in Experiment IV. matter before atrazine application enhanced the adsorption capability of the soil for the herbicide. Baskaran et al. (1996) also reported similar results about the effect of dissolved organic carbon on the sorption and movement of atrazine and 2,4-D by soils. Also Barriuso et al. (1992), showed the importance of endogenous as well as exogenous dissolved organic carbon on the sorption of herbicides by soils.

\section{Conclusions}

Organic pesticides with a weak acid character as 2,4-D $\left(\mathrm{p} K_{\mathrm{a}}=2.8\right)$ are easily leached from soils and sediment components, being frequently detected in surface waters and groundwater (Barceló, 1993). For this reason, it is very important that these compounds remain in the soil, in order to minimise water contamination and also to exert their effects as pesticides a longer time. The application of $\beta$-CD to the soil previously to the addition of $2,4-\mathrm{D}$ can be useful to obtain the effect mentioned above.

On the other hand, the results obtained indicate also the high extracting power of $\beta-C D$ towards the pesticide previously adsorbed on the soil, due to the formation of water-soluble inclusion complexes between 2,4-D and $\beta$-CD. There are some kinds of pesticides (specially low polarity pesticide) which have a high tendency to be adsorbed on soil surfaces, and it leads to their inactivation as pesticides, and sometimes to soil contamination. If these pesticides are able to form inclusion complexes with cyclodextrins and, as a consequence, to increase to their solubility, the application of cyclodextrin solutions to soils with a high concentration of such pesticides adsorbed can increase their removal.

Since there is a great interest in developing systems that can enhance the transport of organic compounds through porous media, thus facilitating remediation, the large affinity of cyclodextrins for a great variety of pesticides makes them possible candidates for use as soil decontaminant.

\section{Acknowledgements}

The authors wish to acknowledge the financial support given by Comisión Interministerial de Ciencia y Tecnología (CICYT) through the research projects AMB95-0904 and AMB97-0692, and to Junta de Andalucía (PAI RNM166).

\section{References}

Abdul, A.S., Gibson, T.L., 1991. Laboratory studies of surfactant-enhanced washing of polychlorinated byphenyl form sandy material. Environ. Sci. Technol. 24, 665-674. 
Abdul, A.S., Gibson, T.L., Rai, D.N., 1990. Use of humic acid solution to remove organic contaminant from hydrogeologic systems. Environ. Sci. Technol. 24, 328-333.

Barceló, D., 1993. Environmental Protection Agency and other methods for the determination of priority pesticides and their transformation products in water. J. Chromatogr. 643, 117-143.

Barriuso, E., Baer, U., Calve, R., 1992. Dissolved organic matter and adsorption-desorption of dimefuron, atrazine and carbetamide by soils. J. Environ. Qual. 21, 359-367.

Baskaran, S., Bolan, N.S., Rahman, A., Tillman, R.W., 1996. Effect of exogenous carbon on the sorption and movement of atrazine and 2,4-D by soils. Aust. J. Soil. Res. 34, 609622.

Brusseau, M.L., Wang, X., Hu, Q., 1994. Enhanced transport of low-polarity organic compounds though soil by cyclodextrin. Environ. Sci. Technol. 28, 952-956.

Businelli, D., 1997. Pig slurry amendment and herbicide coapplication effects on $s$-triazine mobility in soil: An adsorption-desorption study. J. Environ. Qual. 26, 102-108.

Dunnivant, F.M., Jardine, P.M., Taylor, D.L., McCarthy, J.F., 1992. Transport of naturally occurring dissolved organic carbon in laboratory columns containing aquifer water. Soil Sci. Soc. Am. J. 56, 437-444.

Ginés, J.M., Pérez-Martínez, J.I., Arias, M.J., Moyano, J.R., Morillo, E., Ruiz-Conde, A., Sánchez-Soto, P.J., 1996. Inclusion of the herbicide 2,4-dichlorophenoxyacetic acid $(2,4-D)$ with $\beta$-cyclodextrin by different processing methods. Chemosphere 33, 321-334.
Johnson, J.A., Farmer, W.J., 1993. Batch versus column method for detecting distribution of organics between soil and water phases. Soil Sci. Soc. Am. J. 155, 92-99.

Kamiya, M., Nakamura, K., 1995. Cyclodextrin inclusion effects on photodegradation rates of organophosphorus pesticides. Environ. Int. 21, 299-304.

Loukas, Y.L., Antoniadou-Vyza, E., Papadaki-Valiraki, A., Machera, K.G., 1994. $\beta$-Cyclodextrin inclusion complex of a new organophosphorus insecticide. Determination of stability constant with HPLC. J. Agric. Food Chem. 42, 944-948.

Magee, B.R., Lion, L.W., Lemley, A.T., 1991. Transport of dissolved organic macromolecules and their effect on the transport of phenantrene in porous media. Environ. Sci. Technol. 25, 323-331.

Pérez-Martínez, J.I., Morillo, E., Ginés, J.M., 1999. $\beta$-CD effect on 2,4-D soil adsorption. Chemosphere 39, 2047-2056.

Pérez-Rodríguez, J.L., Maqueda, C., Rodríguez-Rubio, P., Jiménez de Haro, M.C., 1996. Occurrence of talc in soils with high iron content from the south-west of Spain. Aust. J. Soil Res. 34, 635-651.

Szejtli, J., 1982. Cyclodextrins and their inclusion complexes. Akadémiai Kiadó, Budapest.

Szente, L., 1998. Stable, controlled-release organophosphorous pesticides entrapped in $\beta$-cyclodextrin. I. Solid state characteristics. J. Thermal Anal. 51, 957-963.

Wang, X., Brusseau, M.L., 1995. Solubilization of some lowpolarity organic compounds by HP- $\beta-C D$. Environ. Sci. Technol. 29, 2632-2635. 